


\section{Outpatient pulmonary rehabilitation}

\author{
S. Singh $h^{1,2}$ \\ K. Wagg ${ }^{1}$ \\ ${ }^{1}$ University Hospitals of Leicester, \\ Leicester and ${ }^{2}$ Coventry University, \\ Coventry, UK
}

\section{Summary}

Pulmonary rehabilitation provides a package of education, nutritional support and physical training that promotes the skills required for patients to successfully self manage their respiratory condition. Improvements in quality of life, exercise tolerance, physical activity and function are key outcomes for the individual. There are many tools available which measure these changes and can be used to identify individual deficits and needs. Most of the literature describes the intervention in chronic obstructive pulmonary disease (COPD), but there is emerging evidence that the benefits translate to other respiratory conditions, and improvements are achievable regardless of disease severity, smoking status, gender or age. To maintain the benefits from rehabilitation it is critical to identify barriers and address behaviour change that will provoke better lifestyle choices.
Outpatient pulmonary rehabilitation is the most frequently described treatment for patients with chronic respiratory disease. The type of rehabilitation varies widely across the globe; however, the content is broadly similar and the aims of rehabilitation are consistent regardless of the precise nature or location of the intervention. The universal aims of rehabilitation are to improve an individual's exercise performance to enhance functional performance, improve quality of life and reduce the overall impact of the disease at the time of rehabilitation and in the future. The latter is achieved by a process of self-management and education integrated into the process of delivery rehabilitation. In the current financial climate is has become increasingly important to document the economic health benefits of rehabilitation, reflected in reduced health care costs accrued after completion of the course.

Outpatient rehabilitation refers to a structured and supervised course of individualised exercise training and education that is conventionally offered to small groups of patients. Most of the literature refers to a hospital-based programme, although there is an increase in enthusiasm to deliver pulmonary rehabilitation in the community. Rehabilitation programmes may be offered in a well equipped leisure centre, or in a more informal setting such as a church or village hall. The principles of delivery are extended independent of the location;
Correspondence

S. Singh

University Hospitals Leicester Glenfield Hospital

Groby Road

Leicester

LE3 9QP

UK

Sally.singh@uhl-tr.nhs.uk

Katy.e.wagg@uhl-tr.nhs.uk

\section{Provenance}

Commissioned article,

peer reviewed.

Competing interests

None declared. 
however, there may be some constraints associated with more informal settings, such as access to aerobic equipment and fewer specialist staff. Therefore, the diversity of the multi-disciplinary education component may be compromised. There may also be a view that high risk patients are best managed in a hospital outpatient programme, but this has not been established in the literature.

Rehabilitation programmes have been well described in the literature $[1,2]$ with a wealth of evidence to support the intervention. The ideal length of a rehabilitation programme has been suggested to be 6-8 weeks [3], although they can be extended to 12 or even 24 weeks [4]. It is suggested that a minimum of 6 weeks is required to provoke an important physiological change and thus an improvement in exercise capacity. Some programmes of a reasonably long duration in excess of 12 weeks do not necessarily provoke a greater response than shorter courses, particularly in the short term. To achieve the desired change in exercise capacity it may be more important to focus on the content and process of the rehabilitation rather than protract the programme. There is some evidence to suggest that an equivalent response can be achieved after a 4 week programme compared with a 7 week programme. Improvements in walking dis-

\section{Figure 1}

Changes in 6-min walking time (6MWT) after a course of rehabilitation [4, 6-16]. $\square$ : change in distance. $\square$ : number of sesssions; _- minimal clinically important difference.

\section{Figure 2}

Changes in the incremental shuttle walking test (ISWT) after a course of rehabilitation [3, 17-20] $\square$ : change in distance. $\square$ : number of sesssions; _ : minimal clinically important difference.
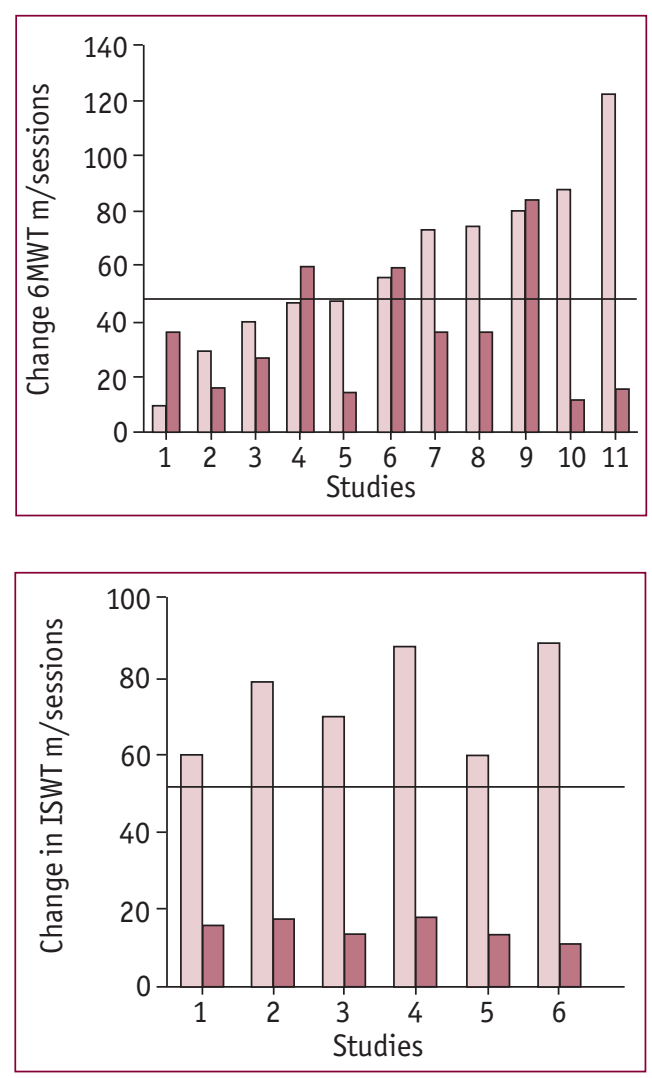

tance were not significantly different for a short 4 week course of rehabilitation compared with a 7 week course after 7 weeks [5]. A sustained course of rehabilitation may have advantages in the longer term, the argument being that an extended course of rehabilitation would encourage a sustained lifestyle change and adoption of regular exercise regimes. Whether there is a direct dose response to rehabilitation has not yet been confirmed, but pressure on healthcare providers almost inevitably means that those paying for the rehabilitation would favour a shorter course (see figures 1 and 2).

\section{Outcome measures}

Measuring the benefits of pulmonary rehabilitation is important to the individual, healthcare professionals and providers and with a careful selection of tools it is possible to satisfy all three. While outcome measures need to be patientcentred and reflect individual change, they should give evidence of the success of the programme and generate data to support development of the service. In the literature, rehabilitation has been traditionally quantified into improvements of exercise tolerance and health-related quality of life. This has more recently been complemented by exploring the impact on the patients' daily activity and completion of domestic tasks, which are likely to be more important to the patient than completing either the incremental shuttle walking test or the 6-min walking test.

\section{Exercise performance}

Assessment of exercise capacity prior to pulmon ary rehabilitation is imperative and both the 6-min walking test [21] and the incremental shuttle walking test are commonly used [22]. The latter is a standardised field test where the patients' performance has been shown to correlate favourably with peak oxygen uptake measured by conventional laboratory maximal exercise tests [23]. This relationship renders the incremental shuttle walk a useful test to predict peak work rate and derive a training programme of $60-85 \%$ of maximal exercise capacity. The individual walking speed can be calibrated against the endurance shuttle walking test [24], a measure of duration of walking at a required speed. However, as of yet there is no established minimal clinically important difference for the endurance walking test. A change of 54 and $48 \mathrm{~m}$ for the 6-min walk and 
incremental shuttle walk tests, respectively $[25$, 26] have been defined as the minimal improvement required for patient improvement. The combination of the incremental and endurance walking tests allow prescription of an aerobic training programme and provide standardised, reproducible and meaningful outcome measures.

\section{Health-related quality of life}

Quality of life can be dissected into several components including symptoms, functional status, mood and social factors. Identifying impairment of these components is essential to recognise their contribution to the vicious cycle of lung disease. Quality of life is an important outcome as it is meaningful to patients and can be utilised in the evaluation of economic activity. There are both generic and disease specific questionnaires available that have been validated in COPD. The St George's Respiratory Questionnaire [27], the Chronic Respiratory Questionnaire [28] and the Self-Reported Chronic Respiratory Questionnaire [29] are the most commonly used. They have shown sensitivity to pulmonary rehabilitation and minimal clinically important differences have been established. For non-COPD patients, more generic questionnaires, such as the Short Form 36, may be more applicable, although the disease specific questionnaires are frequently used.

\section{Strength}

Several studies have reported strength as an important outcome for rehabilitation, this is perhaps the next level of sophistication in outcome measures; however, it is rapidly increasing in popularity. A change in strength in the region of $20 \%$ is anticipated during rehabilitation, although a threshold defining effectiveness has not been established [30]. A computer assisted dynamometer or isokinetic dynamometer is considered the gold standard measure of strength and there are reference values available [31]. However, this equipment is expensive and the relationship with functional capacity is not clear. While other devices such as the hand held dynamometer or strain gauge may have more variability, the low cost and practicality of these tools causes them to be more favourable in clinical practice. Error in the application of these devices can be reduced by standardising the position of the patient during testing. Equally, respiratory muscle strength can be an important outcome, particularly for patients with documented respiratory muscle weakness.

\section{Activity}

The loss of physical activity in patients with COPD has attracted considerable attention recently. A large prospective cohort study [32] found that patients with COPD that self-report very low levels of physical activity were at an increased risk of hospital admission and mortality. However, it is human nature that just because we have the capacity to be more active does not mean we will be, and of how change in exercise performance on standard field tests translates into change in daily activity patterns has not yet been established. This is largely because of the complexity of capturing this type of data. Activity questionnaires, such as the Duke Activity Status Index [33], have been validated in COPD, and although simple to administer, they remain a form of subjective data collection. Some recent studies have reported the benefits of rehabilitation using sophisticated motion detectors $[6,34]$ and although they can yield interesting data, their expense renders them unfavourable outcome measures for standard rehabilitation and of perhaps more use in the research environment.

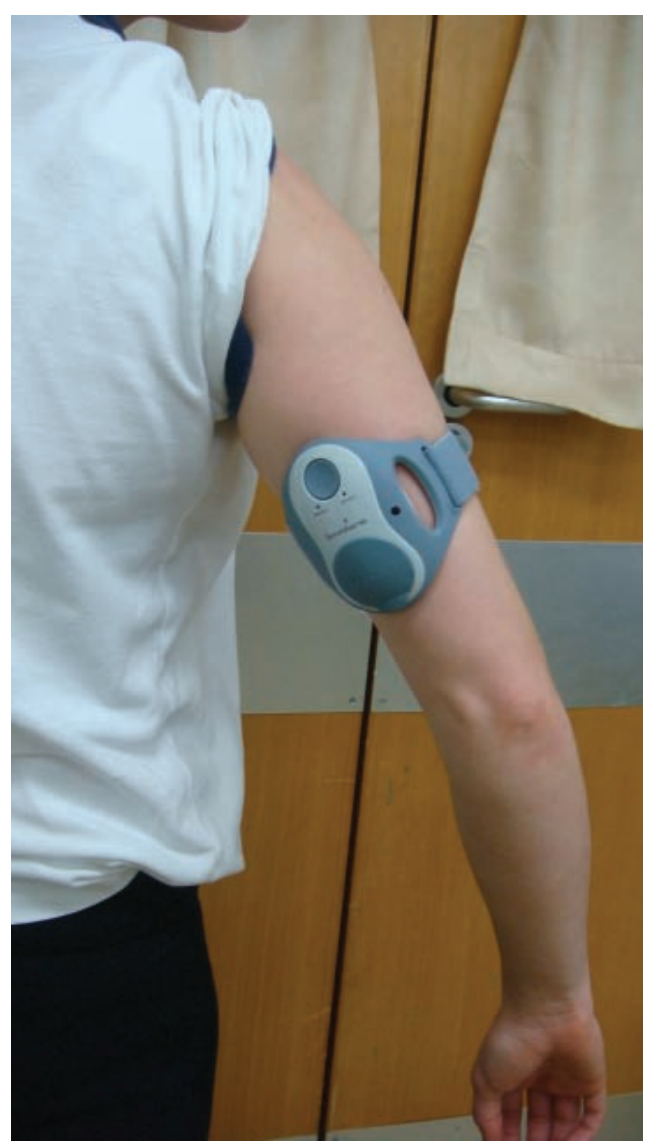




\section{Health economics}

Information for cost effective analysis is not commonly collected as standard practice, however it may be required for audit purposes or to support applications for service development. Data from the Short Form 36 and EuroQoL are necessary to calculate quality adjusted life years to measure the benefits against the cost of the intervention. Previous analyses have favoured rehabilitation [35].

\section{Assessment}

Patients with COPD commonly report symptoms of dyspnoea on exertion, fatigue, reduced exercise tolerance, impaired health-related quality of life and activities of daily living. These factors are not necessarily related to disease severity as indicated by lung function therefore there are other contributory aspects that need to be identified from rigorous and detailed assessment.

Although much of the literature surrounds patients with COPD, there is an emerging body of evidence to suggest patients with other respiratory disorders benefit from rehabilitation [36, 37]. Recent studies suggest that those with less advanced disease can benefit from rehabilitation [38]. One study [39] found that a community based rehabilitation programme improved quality of life, reduced dyspnoea and improved functional exercise capacity in patients with milder airway obstruction whose exercise tolerance was limited. Although these benefits receded after the initial 4 months, the difference between the rehabilitation and control groups were still significant after 2 yrs. The consensus is that rehabilitation should be offered to all patients who have persistent respiratory symptoms and impaired physical function due to dyspnoea despite pharmacological optimisation. The benefits of rehabilitation are achievable regardless of age, sex, smoking status or lung function.

Initial assessment should consider individual

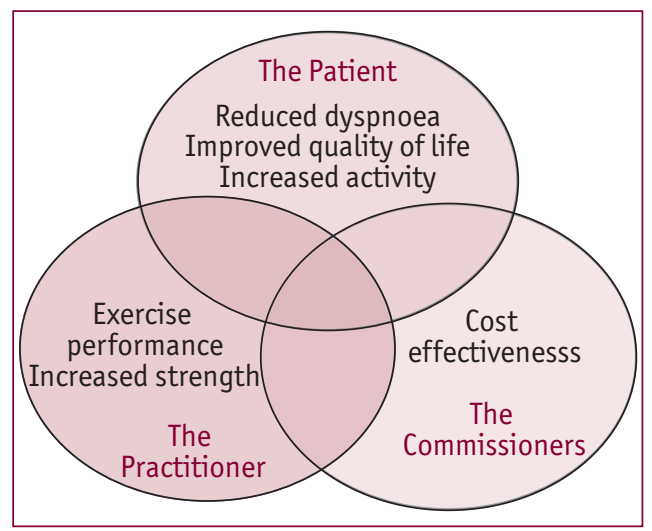

suitability and identify pharmacological, nutritional and oxygen supplementation requirements. Baseline measurements should be taken in order to calculate a training programme and provide comparisons for meaningful outcomes. Success cannot be predicted from baseline measures, however there is evidence to suggest that risk of drop out is greater in depressed patients [40], therefore addressing this prior to rehabilitation may be of value. A generic screening tool for anxiety and depression, such as the Hospital Anxiety and Depression Scale [41], can be used for this purpose.

\section{Components of the pul- monary rehabilitation programme}

The American Thoracic Society/European Respiratory Society guidelines [1] on pulmonary rehabilitation suggest the exercise component of pulmonary rehabilitation includes the following.

- A minimum of 20 sessions, three times per week, two of which to be supervised.

- High intensity exercise to produce greater physiological benefit.

- Interval training may be useful.

- Upper and lower extremity training.

- A combination of endurance and strength training has multiple beneficial effects and is well tolerated.

Rehabilitation should be supported by a multi-disciplinary team. The individual overseeing the programme is commonly a physiotherapist or nurse. Additional important members of the team should include occupational therapists, dieticians, doctors, psychologists, exercise physiologists, respiratory physiology technicians, patient support groups, patient volunteers, smoking cessation officers, benefits agencies and the family and carers.

\section{Endurance training}

The most accessible form of exercise and most important activity to patients is walking [34], which as previously discussed is easy to measure and prescribe with standard field tests. This treatment is inexpensive and is regularly adopted throughout the UK. The use of bicycles and other exercise equipment can form a varied training programme. The target work rate is $60-85 \%$ peak exercise capacity for $30 \mathrm{~min}$, however this is rarely immediately achievable and shorter 
exercise times are a suitable modification to maintain the training effect.

\section{Strength training}

For patients with moderate and severe COPD quadriceps strength has been linked with mortality [42] and maintenance of peripheral muscle function is considered important. Incorporation of resistance training increases muscle strength and there is evidence to suggest it enhances performance of daily activities above endurance training alone [43]. Training usually consists of two to four sets of 6-12 repetitions with a training load of $50-80 \%$ of the patient's maximum weight.

\section{Nutritional support}

Patients with COPD face a worse prognosis if they are underweight or experience weight loss. A number of reviews in this area suggest that nutritional support adds little benefit in terms of weight gain, body composition and exercise capacity. A recent study demonstrated the benefit of a combined counselling and food fortification approach for underweight patients [44]. The study was conducted separately to a rehabilitation programme. The traditional approach uses nutritional support to impact upon weight loss and improve fatfree mass. More recently, the literature has begun to explore the value of nutritional supplementation to enhance performance, not dissimilar to the approach adopted in the sports world, although the evidence is inconclusive [45]. Creatine, commonly used in the sports world to improve performance, has been used individuals with COPD, but no additional benefits over and above conventional rehabilitation were observed [30].

\section{Self-management and educational advice}

A home care exercise programme is of particular importance to a rehabilitation programme with the ultimate aim being 30 min of exercise/brisk walking 5 days per week, in line with many government guidelines. This is not achievable for many patients, however all participants should be encouraged to extend their walking times gradually. The educational programme covers a number of topics including chest clearance, exacerbation management (rehabilitation may also be the

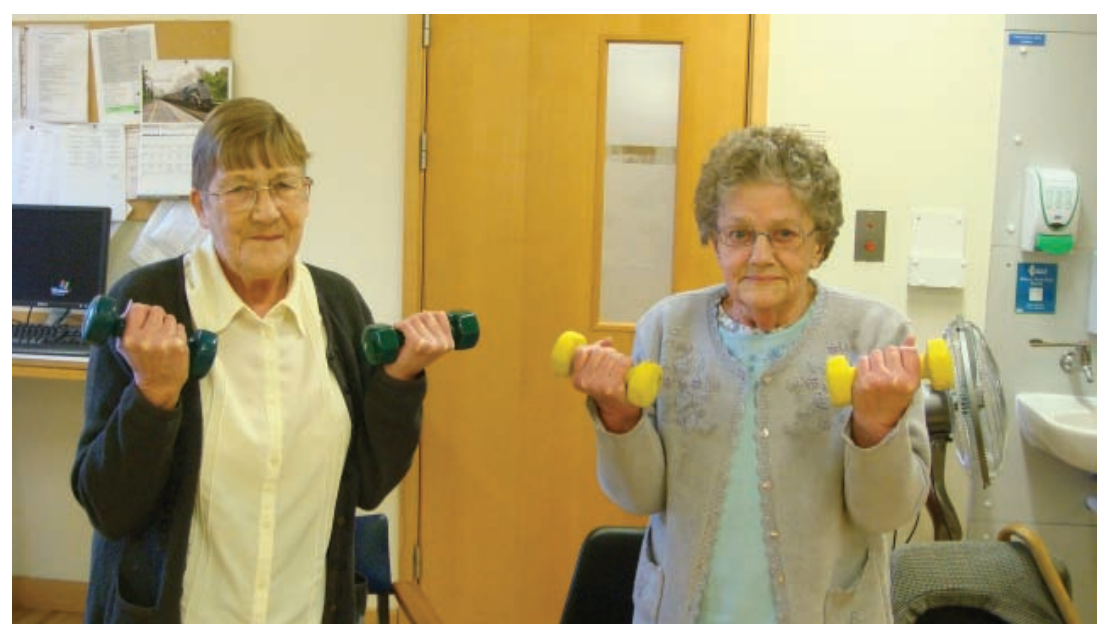

forum to provide patients with an action plan), inhaler technique, relaxation advice, breathing control, tests and travelling and managing physical activity. Other advice may also be given, for example smoking cessation support services. The agenda is to equip the individual with the knowledge and skills to self-manage their disease. There is no preferred definition of self-management and the term is often used interchangeably with self-care. Fundamentally, self-management is a process of knowledge acquisition that provokes important lifestyle changes, which is the aim of rehabilitation. The most recent Cochrane review suggested this is an area in need of further exploration [46].

Maintaining lifestyle changes is the main challenge for those in rehabilitation. Most commonly, it is the change in physical activity that is targeted after discharge; however, the optimal strategy to achieve this has not yet been described. The options range from repeating the course of rehabilitation at regular intervals [47], to telephone support and maintenance groups that meet less frequently than the original programme [48]. Interestingly, the RiEs et al. [49] study found that patients who entered the rehabilitation programme continued to be regular walkers independent of whether they were allocated to the intervention (maintenance) group or the control group. It would seem that it is therefore important to understand the principles of behaviour change and address barriers to continued exercise during the rehabilitation programme. It may also be likely that a range of maintenance options be available to suit the requirements of the individual patient. 


\section{Educational Questions}

1. Pulmonary rehabilitation aims to

a. Improve functional performance (6MWT, ISWT)

b. Improve spirometry c. Improve quality of life d. Improve physical activity

2. Rehabilitation should offer endurance training, which of the following is not true a. Interval training can be considered

b. Lower limb endurance training is an important component of rehabilitation c. The target work rate is between 45 and $85 \%$ d. Upper limb training should be considered

3. Which of the following patients should be excluded from rehabilitation?

a. MRC grade 5

b. Current smokers

c. Those over 80 years old d. Recent myocardial infarction

4. How should strength training be delivered?

a. 5 repetitions with a load $50-80 \%$ of maximum b. To the patients tolerance, with weight selected by the therapist

c. 6-12 repetitions with a load $50-80 \%$ of maximum d. With resistive bands

\section{References}

1. Nici L, Donner C, Wouters E, et al. American Thoracic Society/European Respiratory Society statement on pulmonary rehabilitation. Am J Respir Crit Care Med 2006; 176: 1390-1413.

2. Ries AL, Bauldoff GS, Carlin BW, et al. Pulmonary rehabilitation: joint ACCP/AACVPR evidence-based clinical practice guidelines. Chest 2007; 131, Suppl. 5, 4S-42S.

3. Griffiths TL, Burr ML, Campbell IA, et al. Results at 1 year of outpatient multidisciplinary pulmonary rehabilitation: a randomised controlled trial. Lancet 2000; 355: 362-368.

4. Troosters T, Gosselink R, Decramer M. Short- and long-term effects of outpatient rehabilitation in patients with chronic obstructive pulmonary disease: a randomized trial. Am J Med 2000; 109: 207-212.

5. Sewell I, Singh SJ, Williams JEA, et al. How long should outpatient pulmonary rehabilitation be? A randomized controlled trial of four-weeks versus seven-weeks. Thorax 2006; 61: 767-771.

6. Pitta F, Troosters T, Probst VS, et al. Are patients with COPD more active after pulmonary rehabilitation? Chest 2008; 134: $273-280$.

7. Troosters T, Casaburi R, Gosselink R, et al. Pulmonary rehabilitation in chronic obstructive pulmonary disease. Am J Respir Crit Care Med 2005; 172: 19-38.

8. Cambach W, Chadwick-Straver RV, Wagenaar RC, et al. The effects of a community-based pulmonary rehabilitation programme on exercise tolerance and quality of life: a randomized controlled trial. Eur Respir J 1997; 10: 104-113.

9. Ringbaek TJ, Brondum E, Hemmingsen L, et al. Rehabilitation of patients with chronic obstructive lung disease. Are two exercise sessions per week sufficient? Ugeskr Laeger 2000; 162: 498-501.

10. Engstrom CP, Persson LO, Larsson S, et al. Long-term effects of a pulmonary rehabilitation programme in outpatients with chronic obstructive pulmonary disease: a randomized controlled study. Scand J Rehabil Med 1999; 31: $207-213$.

11. Finnerty JP, Keeping I, Bullough I, et al. The effectiveness of outpatient pulmonary rehabilitation in chronic lung disease: a randomized controlled trial. Chest 2001; 119: 1705-1710.

12. Solanes I, Guell R, Casab P, et al. Duration of pulmonary rehabilitation to achieve a plateau in quality of life abd walk test in COPD. Respir Med 2009; 103: 722-728.

13. Bendsttrupp KE, Ingemann JJ, Holn S, et al. Out-patient rehabilitation improves activities of daily living, quality of life and exercise tolerance in chronic obstructive pulmonary disease. Eur Respir J 1997; 10: 2801-2806.

14. Guell R, Casan P, Belda J, et al. Long-term effects of outpatient rehabilitation of COPD: a randomized trial. Chest 2000; 117: 976-983.

15. Riario-Sforza GG, Incorvaia C, Paterniti F, et al. Effects of pulmonary rehabilitation on exercise capacity in patients with COPD: a number needed to treat study. Int J Chron Obstruct Pulmon Dis 2009; 4: 315-319.

16. Karapolat H, Atasever A, Atamaz F, et al. Do the benefits gained using a short-term pulmonary rehabilitation program remain in COPD patients after participation? Lung 2007; 185: 221-225.

17. Man WD, Polkey MI, Donaldson N, et al. Community pulmonary rehabilitation after hospitalisation for acute exacerbations of chronic obstructive pulmonary disease: randomised controlled study. BMJ 2004; 329: 1209.

19. Wedzicha JA, Bestall JC, Garrod R, et al. Randomized controlled trial of pulmonary rehabilitation in severe chronic obstructive pulmonary disease patients, stratified with the MRC dyspnoea scale. Eur Respir J 1998; 12: 363-369.

20. Green RH, Singh SJ, Willaims J, et al. A randomised controlled trial of four weeks versus seven weeks of pulmonary rehabilitation in chronic obstructive pulmonary disease. Thorax 2001; 56: 143-145.

21. Jenkins SC. 6-minute walk test in patients with COPD: clinical applications in pulmonary rehabilitation. Physiotherapy 2007; 93: 173-180.

22. Bestall JC, Paul EA, Garrod R, et al. Longitudinal trends in exercise capacity and health status after pulmonary rehabilitation in patients with COPD. Respir Med 2003; 97: 173-180.

23. Singh SJ, Morgan MD, Scott S, et al. Development of a shuttle walking test of disability in patients with chronic airways obstruction. Thorax 1992; 47: 1019-1024.

24. Singh SJ, Morgan MD, Hardman AE, et al. Comparison of oxygen uptake during a conventional treadmill test and the shuttle walking test in chronic airflow limitation. Eur Respir J 1994; 7: 2016-2020.

25. Revell SM, Morgan MD, Singh SJ, et al. The endurance shuttle walk: a new field test for the assessment of endurance capacity in chronic obstructive pulmonary disease. Thorax 1999; 54: 213-222.

26. Singh SJ, Jones PW, Evans R, et al. Minimum clinically important improvement for the incremental shuttle walking test. Thorax 2008; 63: 775-777.

27. Redelmeier DA, Bayoumi AM, Goldstein RS, et al. Interpreting small differences in functional status: the six minute walk test in chronic lung disease patients. Am J Respir Crit Care Med 1997; 155: 1278-1282.

28. Jones PW, Quirk FH, Baveystock CM, et al. A self-complete measure of health status for chronic airflow limitation. The St George's Respiratory Questionnaire. Am Rev Respir Dis 1992; 145: 1321-1327.

29. Guyatt GH, Berman LB, Townsend M, et al. A measure of quality of life for clinical trials in chronic lung disease. Thorax 1987; 42: 773-778.

30. Williams JE, Singh SJ, Sewell L, et al. Development of a self-reported Chronic Respiratory Questionnaire (CRQ-SR). Thorax 2001; 56: 954-959.

31. Deacon SJ, Vincent EE, Greenhaff PL, et al. Randomised controlled trial of dietary creatine as an adjunct therapy to physical training in COPD. Am J Respir Crit Care Med 2008; 1: 233-239.

32. Neder JA, Nery LE, Shinzato GT, et al. Reference values for concentric knee isokinetic strength and power in nonathletic men and women from 20 to 80 years old. J Orthop Sports Phys Ther 1999; 29: 116-126.

33. Garcia-Aymerich J, Lange $P$, Benet $M$, et al. Regular physical activity reduces hospital admission and mortality in chronic obstructive pulmonary disease: a population-based cohort. Thorax 2006; 61: 772-778.

34. Hlatky MA, Boineau RE, Higginbotham MB, et al. A brief self-administered questionnaire to determine functional capacity (the Duke Activity Status Index). Am J Cardiol 1989; 64: 651-654.

35. Sewell L, Singh SJ, Williams JE, et al. Can individualized rehabilitation improve functional independence in elderly patients with COPD? Chest 2005; 128: 1194-1200.

36. Griffiths TL, Phillips CJ, Davies S, et al. Cost effectiveness of an output multidisciplinary pulmonary rehabilitation programme. Thorax 2001; 56: 779-784.

37. Halland AE, McDonald CF. Pulmonary rehabilitation and interstitial lung disease. Thorax 2009; 64: 548.

38. Salhi B, Troosters T, Behaegel M, et al. Effects of pulmonary rehabilitation in patients with restrictive lung disease. Chest 2010; 137: 273-279.

39. Evans RA, Singh SJ, Collier R, et al. Pulmonary rehabilitation is successful for COPD irrespective of MRC dyspnoea grade. Respir Med 2009; 103: 1070-1075. 
40. van Wetering CR, Hoogendoorn M, Mol SJ, et al. Short- and long-term efficacy of a community-based COPD management programme in less advanced COPD: a randomised controlled trial. Thorax 2010; 65: 7-13.

41. Garrod R, Marshall J, Barley E, et al. Predictors of success and failure in pulmonary rehabilitation. Eur Respir J 2006; 27: 788-794.

42. Zigmond AS, Snaith RP. The hospital anxiety and depression scale. Acta Psychiatr Scand 1983; 67: 361-370.

43. Swallow EB, Reyes D, Hopkinson NS, et al. Quadriceps strength predicts mortality in patients with moderate to severe chronic obstructive pulmonary disease. Thorax 2007; 62: 115-120.

44. Philips WT, Benton MJ, Wagner CL, et al. The effect of single set resistance training on strength and functional fitness in pulmonary rehabilitation patients. J Cardiopulm Rehabil 2006; 26: 330-337.

45. Weekes CE, Emery PW, Elia M. Dietary counselling and food fortification in stable COPD: a randomised trial. Thorax 2009; 64: 326-331.

46. Steiner MC, Barton RL, Singh SJ, et al. Nutritional enhancement of exercise performance in chronic obstructive pulmonary disease: a randomised controlled trial. Thorax 2003; 58: 745-751.

47. Effing T, Monninkhof EM, van der Valk PD, et al. Self-management education for patients with chronic obstructive pulmonary disease. Cochrane Database Syst Rev 2007; 4: CD002990.

48. Foglio K, Bianchi L, Ambrosino N. Is it really useful to repeat outpatient pulmonary rehabilitation programs in patients with chronic airway obstruction? A 2-year controlled study, Chest 2001; 199: 1696-1704.

49. Ries AL, Kaplan RM, Myers R, et al. Maintenance after pulmonary rehabilitation in chronic lung disease: a randomised trial. Am J Respir Crit Care Med 2003; 167: 880-888. 